\title{
Assujeitamento e disrupção de um corpo que permanece e resiste: possibilidade de existência de uma travesti no ambiente escolar
}

\author{
Subjection and disruption of a body that remains and resists: possibility \\ of a transvestite in the school environment
}

\section{Assujetamientos y disrupción de un cuerpo que permanece y resiste: posibilidad de existencia de una travesti en el ambiente escolar}

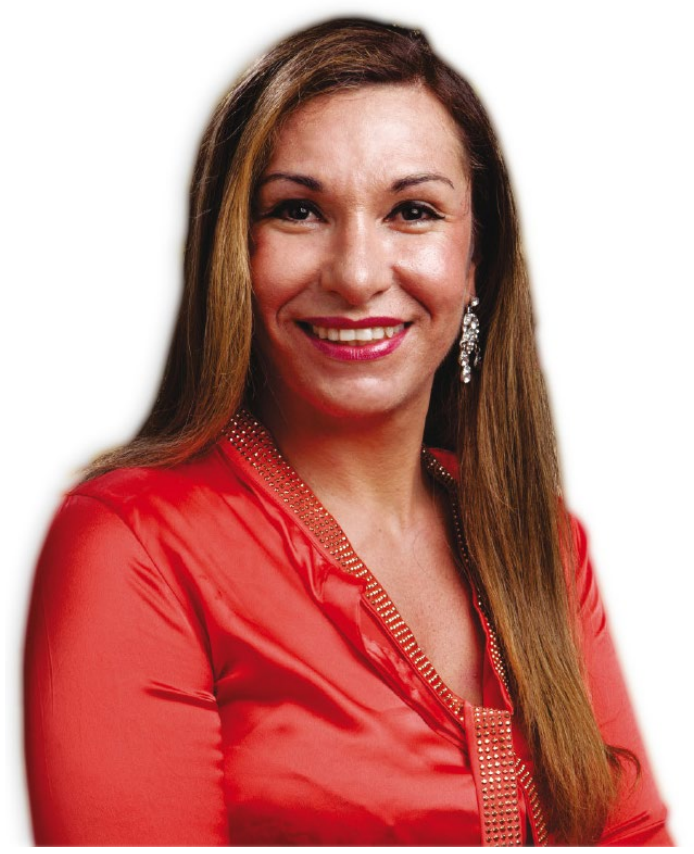

Em entrevista à Reciis, Luma Nogueira de Andrade traça uma trajetória discursiva e interseccional entre a sua vivência e a pesquisa científica, iniciada no campo das ciências biológicas. Os estudos e os estranhamentos do conhecimento biológico, especificamente sobre o corpo e a sexualidade, levaram a pesquisadora a construir críticas desse conhecimento em diálogo com o campo das ciências humanas. No doutorado, sua existência e corporeidade, construídas no interior do estado do Ceará, a convocam para dissertar, na linguagem científica, sobre as outras possibilidades de ser travesti. Refletida no seu sujeito de pesquisa, Luma discute sobre a disciplina e a resistência de jovens travestis às normas educacionais, propondo, a partir do disciplinamento dos corpos marcados pelo espaço escolar, a possibilidade de fuga e de algumas táticas para se fazer existir também nesse lugar. Luma Nogueira de Andrade é professora decana do curso de pedagogia da Universidade da Integração Internacional da Lusofonia Afro-Brasileira.

Palavras-chave: Educação; Sexualidade; Gênero; Diversidade sexual; Travestilidade.

Keywords: Education; Sexuality; Gender; Sexual diversity; Trasvestility.

Palabras clave: Educación; Sexualidad; Género; Diversidad sexual; Travesti. 
Este texto compõe o Dossiê: 40 anos do movimento LGBT no Brasil: comunicação, saúde e direitos humanos.

Entrevistador: Roberto Abib.

Fotografia: divulgação.

Licença CC BY-NC atribuição não comercial. Com essa licença é permitido acessar, baixar (download), copiar, imprimir, compartilhar, reutilizar e distribuir os artigos, desde que para uso não comercial e com a citação da fonte, conferindo os devidos créditos de autoria e menção à Reciis. Nesses casos, nenhuma permissão é necessária por parte dos autores ou dos editores.

Reciis: No campo da pesquisa, você inicia com uma discussão que envolve questões que tratam do meio ambiente. Como surgiu esse interesse? É um campo importante em seus estudos?

Luma Andrade: Nasci de uma família carente do interior do estado do Ceará, filha de agricultores analfabetos; de pessoas que viviam mais no campo. Elas não tinham muita perspectiva de estar em outro lugar se não naquele, até por conta da situação de pobreza. A educação na época não era tida como algo importante. Na verdade, as famílias queriam ter muitos filhos para poder agregá-los exatamente no campo para as atividades agrícolas. Então, fui a única da minha família a conseguir sair desse contexto. Fui em busca da educação, tendo como incentivadora minha genitora. Então, a trajetória inicial de minha pesquisa vem da minha vivência, da relação com a terra e da proximidade com o meio ambiente.

Fui em busca da universidade mais próxima de minha cidade, Morada Nova (CE), na qual não tinha universidade pública nem particular. Segui para a cidade vizinha chamada Limoeiro do Norte (CE), um polo do desenvolvimento da região do Vale do Jaguaribe, no interior do estado. Submeti-me ao processo seletivo da Universidade Estadual do Ceará, no campus que tem em Limoeiro, e fiz o curso com o qual tinha mais afinidade: Licenciatura Plena em Ciências. Só ao final da formação tive que escolher se iria para área de biologia e química ou física e matemática. Então, de acordo com a minha trajetória no campo e afinidade com o meio ambiente, optei pela biologia; isso também pelo interesse em conhecer mais sobre o corpo humano. Devido à carência de docente na área de ciências, antes mesmo de concluir a graduação já estava atuando nas escolas e continuei buscando sempre aperfeiçoar meus conhecimentos.

Surgiu a oportunidade de fazer o mestrado em outro estado, na Universidade Estadual do Rio Grande do Norte (UERN), em Mossoró. Várias pessoas da cidade onde nasci tinham tentado esse mestrado, já que era o mais próximo e tinha relação com o meio ambiente. Percebi que esse curso se alinhava um pouco com a minha formação e com os meus interesses. As oportunidades foram surgindo e fui agarrando. Inclusive, vários de meus professores, professoras e ex-professores tentaram ser aprovados nesse mestrado. Busquei apoio desses professores para ter acesso ao material de estudo, ou mesmo estudar com eles, mas a rejeição foi imediata. Previam que eu não teria a possibilidade de ser aprovada. Porém, fui a única a passar no processo. Fui aprovada no mestrado em Desenvolvimento e Meio Ambiente da UERN.

A pesquisa que desenvolvi foi focada na poluição do Rio Banabuiú, um rio que existe na cidade onde nasci. Analisei a poluição do rio pelas águas residuárias ${ }^{1}$. Assim, produzi algo dessa natureza e isso contribuiu para a disseminação de saberes, inclusive, entre meus alunos do ensino fundamental e médio através de aulas teóricas e práticas. 

trata das temáticas de gênero, diversidade sexual e educação?

Luma Andrade: O período em que pesquisava e lecionava no campo das ciências biológicas foi muito importante para minha aprendizagem, porque nele é costume ter uma formação muito cartesiana. Os estudos da biologia a que tive acesso não produziam relação com outros saberes como os da sociologia, filosofia e antropologia. O contato com esse campo da biologia, das ditas, no passado, ciências exatas, e hoje com as ciências da natureza, matemática e suas tecnologias, me possibilitou produzir saberes bem específicos sobre o citado campo; me potencializou muito, inclusive, com um olhar crítico sobre a biomedicina tradicional. Ao mesmo tempo em que tinha contato com aquele conhecimento, eu ia estranhando muita coisa, pois a minha existência não era daquele jeito, não estava de acordo. Um exemplo: a forma como os órgãos sexuais são abordados na escola ao determinar que tipos de órgãos podem ser sexuais e quais tipos não podem ser sexuais. Quando se afirma qual órgão é sexual, ocorre a determinação daqueles que não podem ser. Isso tudo entra num contexto de adestramento para determinar a normatização de quais órgãos podem ser manipulados para o sexo e, além disso, quais os que podem interagir. Assim é produzida uma ditadura heterossexual ou mesmo uma 'ideologia de gênero’ imposta a todos, com fundamentação nos livros didáticos. Na disciplina de ciências na sétima série do ensino fundamental, o corpo humano é tratado nessa perspectiva. Lá no terceiro ano do ensino médio, a questão retorna com a genética, determinando sexo e gênero pela ideia de cromossomos. Mas observe: temos a possibilidade de utilizar outros órgãos do corpo como sexuais como o ânus e a boca, e isso não é considerado. Não são os cromossomos que determinam sexo e gênero nas relações sociais, eles nunca foram importantes para determinar o que eu sou, por exemplo. A partir dessas análises, fissuras foram produzidas pela análise crítica. Ao mesmo tempo em que estava assimilando o conhecimento cartesiano das ciências, eu começava a refletir sobre essas realidades que estavam se contrapondo.

Isso me ajudou muito a produzir uma análise crítica sobre o que era ensinado dentro de sala de aula, dentro desse campo, de uma ciência exata, do pensamento biológico, porque esse pensamento biológico fundamenta muito a ideia do patriarcado. Ele vai se associar a todo esse contexto social das instituições disciplinares para poder enquadrar determinados sujeitos em um determinado lugar, dizer o que é permitido, determinar tradicionalmente o que é imposto a todos em termos de normas sociais. As normas sociais conservadoras e tradicionais se manifestam também no contexto da ciência, do jurídico e da escola como forma de legitimá-las e acabamos as reproduzindo de forma 'automática' sem uma análise crítica.

Assim, na formação em meio ambiente, comecei a entrar em contato com essas criticidades e passei a ler algumas obras na área da sociologia, filosofia e antropologia. Posteriormente, comecei a entrar em outra linha de pesquisa com o objetivo de buscar o doutorado. Mas queria que o estudo fosse voltado para a área de educação. Fiz o doutorado em educação pela Universidade Federal do Ceará. Já me identificava enquanto travesti. Tinha um corpo, inclusive, com próteses de seios, bem mais aperfeiçoado do que quando iniciei o processo no final do ensino fundamental. Não foi algo que construí após o sucesso escolar e profissional, pois algumas pessoas poderiam imaginar que conquistei tais espaços antes de realizar a transformação. Comigo não foi assim. Vivi e vivo uma contínua batalha pela sobrevivência, principalmente nesses espaços disciplinadores e de controle.

No final do mestrado, comecei a entrar em contato com algumas produções que foram feitas por alguns pesquisadores e pesquisadoras que só viam o lugar das travestis na prostituição. Não era algo só de senso comum, era algo que estava sendo legitimado pelo conhecimento científico. Os trabalhos falavam disso: das travestis nas grandes metrópoles e de sua ligação com o campo da prostituição ${ }^{2,3}$. Eu pensava: "Mas eu estou no interior, sou uma pessoa que não está nas grandes metrópoles, não me constituí nas 
grandes cidades. E sou uma pessoa que se identifica como travesti e não busca a prostituição como uma saída para a própria vida”. Não estou querendo dizer com isso que esses estudos não foram importantes, quero dizer que existia uma hegemonia na questão do conhecimento em relação às travestis, por elas serem identificadas apenas nas grandes metrópoles ou nos campos de prostituições. Todos os trabalhos que tinham sido produzidos na época, e também não eram tantos, expressavam esse pensamento naturalizado. Em relação às formas da construção do corpo, as técnicas das 'bombadeiras' eram fundamentais. Uma realidade que não era a que eu vivenciava nem a de minhas colegas interlocutoras, pois onde vivíamos e como vivíamos não tínhamos acesso a tais tecnologias. Então contrariávamos tais pensamentos generalizados pelo fato de que não vivenciávamos a travestilidade em grandes metrópoles, não vivíamos da prostituição e não nos construíamos com as técnicas das 'bombadeiras'. Não queria negar a existência das outras, mas também não queria ser esquecida, negada ou desqualificada por não estar nas regras estabelecidas. Existem outras possibilidades e senti a necessidade de escrever sobre isso.

Na elaboração da proposta do projeto de pesquisa para o doutorado, tive muito cuidado com as normas acadêmicas, porque imaginava que seria muito cobrada por isso, a produzir um conhecimento de acordo com a língua. Às vezes, queremos dizer algo que a língua não dá conta. Queremos trazer algo que não conseguimos expressar na fala, pois exige um novo código de linguagem. Às vezes, temos que escapar da linguagem oficial para não reproduzir as mesmas ideias. O silenciamento é muito forte na nossa linguagem. Na tradição acadêmica, somos muito cobrados a estarmos de acordo com as normas, assim como acontece na vida.

Sob orientação inicial de Daniel Lins'i tive contato com a filosofia da diferença, principalmente a partir de filósofos como Foucault e Deleuze, conseguindo refletir tal conhecimento articulado com a minha vivência e a de outras travestis. Foi a partir daí que me libertei plenamente do campo das ciências exatas, ciências da natureza e suas tecnologias para outro olhar mais antropológico, sociológico e filosófico. O importante disso é que tive a oportunidade de construir uma formação interdisciplinar, que me permite ter a percepção do olhar das ciências da natureza e das humanas. Isso foi extremamente importante porque, até na minha produção, consegui ter uma análise crítica dessa visão biológica que também é atravessada pelo meu modo de ser. Trata-se de uma potência que me ajudou muito a construir o conhecimento e a mentalidade que tenho e dissemino nas produções acadêmicas.

\section{Reciis: Inspirada pelo pensamento foucaultiano, você problematiza a disciplina escolar e os modos de ser de estudantes jovens travestis. Como é se mover nesse espaço marcado pela disciplina?}

Luma Andrade: O Foucault vai trazer a ideia das instituições disciplinares ${ }^{4,5}$, entre elas está a escola, um lugar onde o poder da disciplina é exercido. Começo a refletir sobre isso e percebo o quanto a minha vivência foi marcada, principalmente no espaço escolar, por esse disciplinamento do corpo e da mente. $\mathrm{E}$ comecei a perceber em que lugar eu podia estar na escola e em que lugar eu não podia estar. Como eu podia estar e como eu não poderia estar. Por exemplo, eu não podia ter acesso, junto com as outras crianças e adolescentes, ao intervalo das aulas, à merenda escolar e às brincadeiras. Eu não tinha esse direito como as demais pessoas.

Eu tinha mais afinidade com as meninas do que com os meninos. Não estou querendo dizer que isso é algo essencialista, algo que nasceu comigo, não é isso. Poderia estar com os meninos e ser a mesma Luma. Mas eu tinha essa empatia com as meninas. Então, brincava com elas, e os meninos, quando viam aquilo,

\footnotetext{
i Sociólogo, filósofo e psicanalista, com doutorado em Sociologia - Université de Paris VII - Université Denis Diderot (1990) e
} pós-doutor em Filosofia, sob a direção de Jacques Rancière, pela Université de Paris VIII (2003). 
estranhavam: "Como você não vai brincar com a gente e vai brincar com as meninas? As meninas brincam com as meninas e os meninos com os meninos". Isso era um pacto e eu não aceitava esse jogo. Então, queria subvertê-lo. Chegou um momento em que fui espancada por um colega que não aceitava. Ele dizia: "Ah, você não vai não, peraí que a gente vai te ajeitar. Te consertar". Ele me espancou. Foi aí que percebi que eu não tinha espaço ali. Não podia ser eu mesma, então, deveria me resguardar. Teria que ter mais cuidado.

Não comentava em casa porque eu tinha medo de dizer e ser penalizada novamente. A família também é uma instituição disciplinar. Se eu chegasse em casa e falasse disso, poderia sofrer a mesma coisa. Poderia sofrer outra surra. Não era isso que eu queria. Então, isso tudo era silenciado. Dessa forma, observo como a disciplina interage com a família e com a religião também. Depois de ter apanhado do colega, uma aluna relatou o ocorrido para a professora, que já estava ciente do que havia acontecido e disse para mim: "Bem feito! Quem mandou você ser assim?”

Outro lugar interditado à minha pessoa era o banheiro. Eu não poderia utilizar o banheiro masculino e não poderia utilizar o banheiro feminino. Eu era uma criança com a performatividade corporal feminina. Desde a infância, quando andava com meus pais, as pessoas confundiam. Minha mãe gostava dos meus cabelos cacheados grandes. O meu pai brigava: "Esse menino de cabelo grande está confundindo o povo". Mesmo quando cortava os cabelos, o corpo continuava expressando uma feminilidade. Isso me fez perceber na escola que eu tinha que ter muito cuidado. Tinha que ficar me controlando porque estava sendo policiada o tempo todo. Não poderia utilizar o banheiro masculino porque os meninos me violentavam e não poderia utilizar o das meninas porque as meninas não aceitavam, nem a gestão da escola permitia. Onde é que eu iria fazer as minhas necessidades fisiológicas? Não tinha onde. O que eu ia fazer? Eu me continha.

Pois bem, não posso ir para o intervalo, não posso ir ao banheiro. Não posso afrontar as pessoas, querer algo, buscar algo. Tenho que ficar na minha. Então, não ia para o intervalo e ficava na sala. Chegou a um ponto em que estudar diurnamente era impossível, porque os alunos eram adolescentes, pegava muito e tal. Eu era muito perseguida. Os gritos. Antigamente eram mais fortes as chacotas. Aquilo tudo.

\section{Reciis: Diante disso, como se consegue dar continuidade aos estudos?}

Luma Andrade: Pensava: "Nossa Senhora, tenho que continuar na escola, tenho que procurar uma vida melhor para mim e para minha família. A única saída é a educação. Não vejo outra saída". Os estudos eram como se fosse uma fuga. Como se eu entrasse no meu mundo e me fechasse, porque isso era permitido. Minha mãe dizia: "Olha, ele não quer namorar, porque está estudando, pensando no futuro”. As pessoas incorporavam esses discursos. Então eu podia, isso era permitido. Entrar no meu mundo e me fechar nele eu poderia. A cobrança de ter namorada era superada em função de estar em outra ótica, no papel de estudar. Assim me assujeitava àquilo que era permitido.

Qual era a minha 'fuga' na escola? Ficava na sala fazendo as tarefas, quietinha lá, pois estudar era permitido. Ninguém iria me importunar. Depois, eu saí do turno diurno da universidade, que eu não suportava. Ia para casa com dores atrozes na bexiga porque tinha que segurar a urina. Aí pensei: "Para conseguir ficar aqui, vou ter que encontrar outra saída". Era ainda muito jovem, uma jovem de 14 anos. Aí pensei assim: "Se eu entrar em contato com adultos, porque com adultos não é tão perverso como era com crianças e adolescentes de minha idade, talvez encontrasse uma saída. Acho que vou pedir para ir para a turma da noite". Assim, sair do turno diurno e ir para o noturno era uma possibilidade de conseguir sobreviver naquele ambiente.

Pedi para a diretora me transferir para o turno noturno. Ela não entendia: "Não, você é um ótimo aluno. Você ainda não tem idade. À noite é para quem é adulto, quem trabalha”. Aquele discurso. Eu dizia: "Não, mas eu preciso!" Falava para minha mãe e ela me apoiava. Eu insistia com a diretora e ela 
dizia que eu não podia porque era criança. As normas não permitiam. Insisti tanto que, enfim, ela me transferiu para a turma da noite.

Aí tive contato com outro público, eram pessoas mais adultas. Foi interessante porque passei a ensinar para aquelas pessoas, porque eu já tinha uma aprendizagem bem mais avançada, mesmo sendo da mesma série. Comecei a perceber que poderia contribuir com eles. A própria professora percebia isso porque as minhas notas eram as melhores da sala, principalmente em matemática. Mesmo assim, essa singularidade feminina ainda impactava, mesmo à noite. Não como era à tarde. À noite era bem mais brando. Mas havia também xingamentos, isso tudo. Então, o que eu encontrei? Ocorreu uma parceria com os meus colegas. Eu os ensinava antes das avaliações, e, em troca, eles me davam proteção. Foi um jogo. O tempo todo jogando. O tempo todo encontrando uma saída. Consegui a afetividade deles dessa forma. Eu os ajudava, eles criavam uma empatia comigo, nos tornávamos mais próximos e eu tinha a proteção. Eles não mexiam e não deixavam ninguém mexer comigo. Estava num lugar mais seguro. Foi assim que consegui terminar o ensino médio.

Dessa forma, me assujeitava a muita coisa, mas ao mesmo tempo, na medida do possível, estava andando, caminhando, com assujeitamento e produzindo resistência. Quando tudo dizia não, eu ia caminhando. Mas aí fui conseguindo, aos poucos, coisas que antes eu não conseguia. Ia conseguindo crédito. Por parte da professora: "Tem as melhores notas e está ajudando os colegas". Assim, poderia fazer coisas que não fazia antes. Chegava a usar o intervalo das aulas. Então, como eu conseguia isso? Me assujeitei; encontrei um jogo e fui andando.

Daí vem o tema da minha tese, posteriormente publicada como livroii: Travestis nas escolas, assujeitamento e resistências à ordem normativa ${ }^{6}$. $\mathrm{O}$ estudo fala muito em se assujeitar e resistir. Nem sempre eu pude resistir. Como muita gente dizia: "Você era para ser resistência o tempo todo". Mas, se fosse resistência o tempo todo, eu não teria escapado. Estamos falando de uma outra época. As pessoas não conseguem perceber isso. Hoje é outra história, hoje é outro contexto. Outros dispositivos. Antes, sequer falava-se dessas questões.

Por isso é que o trabalho é muito atrevido. Ele é muito ousado e, para completar, tinha que cair nas mãos de pessoas que pudessem dar essa potência. Por conta de atividades a serem realizadas em Paris, pelo Daniel Lins, a pesquisa passou a ser orientada pela professora Celecina de Maria Veras Sales ${ }^{\mathrm{iii}}$, que deu grandes contribuições na área da educação, e por Alexandre Flemingiv. Assim, foi possível colocar todo o conhecimento e toda a vivência no papel. Era muita coisa para dizer. Era muita coisa para registrar e o citado livro possibilitou isso.

ii Travestis na escola: assujeitamento e resistência à ordem normativa. Rio de Janeiro: Metanoia; 2015.

iii Doutora em educação pela Universidade Federal do Ceará, pós-doutorado pelo Instituto de Ciências Sociais da Universidade de Lisboa. Atualmente, é professora associada da Universidade Federal do Ceará no Curso de Graduação de Gestão de Políticas Públicas e do Programa de Pós-Graduação de Avaliação de Políticas Públicas e do Programa de Pós-Graduação em Educação.

iv Professor Associado II na Universidade Federal do Ceará e coordenador do Laboratório de Estudos da Oralidade. Na Universidade Federal do Ceará, concluiu bacharelado (com concentração em antropologia), mestrado e doutorado. Atua exclusivamente na área de antropologia. É autor do livro 'O Voo da Beleza: experiência trans e migração'. 
Reciis: Nas escolas em que realizou a pesquisa de doutorado, você aponta que o projeto pedagógico não reconhece as singularidades e a existência das travestis; argumenta sobre a necessidade de livros didáticos sobre a diversidade sexual, um assunto muito discutido ultimamente na sociedade brasileira. Diante de polarizações marcadas pelo bem e o mal, o que é preciso entender nessa junção escola e diversidade sexual?

Luma Andrade: Primeiro, nós temos uma incoerência muito forte: o que é dito na área da educação não é o que é praticado. Escutamos os discursos presentes na legislação, principalmente no artigo $205^{\circ}$ da Constituição Federal, que apresenta a educação como um direito de todos. A escola é dita como uma instituição para todos e também inclusiva. Esse discurso é muito forte quando se trata de educação. Na referida Constituição, a educação se apresenta como um direito fundamental sem qualquer distinção. Na prática, essa educação oferecida pelo Estado vai impossibilitar a existência ou, pelo menos, restringir a existência de pessoas que não estão em acordo com as normas e os padrões hegemônicos para a existência do ser humano. Então, é muito contraditório quando ao mesmo tempo se dá o direito, mas, na prática, há os artifícios e as artimanhas do como fazer essa educação formal e conservadora.

Quando eu não podia utilizar o banheiro, estava sendo submetida a um processo de 'adestramento': "Olha, esse não é o lugar para você. Se você quer fazer suas necessidades fisiológicas, se adeque ou saia daqui”. Era isso que me diziam sem me revelar verbalmente, mas na prática do fazer das relações sociais. Quando não podia ir para o intervalo como os outros colegas, entendia isto: "Esse não é o lugar para você." Como refúgio e resistência, ficava na sala de aula estudando.

A sistemática da escola vai revelar que ela não é lugar para a diversidade sexual. Isso vai estar presente também nos livros didáticos. Neles, não encontramos ainda espaço para falar sobre essa temática de uma forma, pelo menos, superficial. Quando você pega o livro de ciências da sétima série que trata do corpo humano, essas questões serão trabalhadas diante de uma visão totalmente heteronormativa do corpo e dos comportamentos das pessoas. Então o que é isso? O fato de excluir tal temática do diálogo na escola impõe uma única forma de ser, no caso, heterossexual. Não é permitido tratar da diferença porque é algo inaceitável para sociedade conservadora.

Acompanho alguns projetos políticos pedagógicos de escolas públicas e noto que até hoje, com todo esse avanço, há projetos que não apresentam nada sobre diversidade sexual. Fazem referências de uma forma generalizada: a escola é um espaço para todos. Tem que existir a educação para o respeito, não permitindo a discriminação e o preconceito. Então, se no currículo escolar isso não tem espaço, nos livros didáticos não aparece, e o professor não tem informação para trabalhar essas questões porque também na universidade não foram incluídas disciplinas com a temática, tudo vai sendo conduzido de forma racionalizada para manutenção de geração em geração do pensamento hegemônico. Até mesmo na formação continuada dos docentes não se vê as questões de gêneros e sexualidades como relevantes por muitos profissionais nas escolas. Ou seja, nós temos um descaso completo do Estado, descaso absoluto e institucionalizado, que contribui para impedir as discussões sobre gêneros e diversidade sexual principalmente com as ideias tradicionais de escola sem partido e ideologia de gênero.

Mesmo conquistando um dispositivo legal para as escolas trabalharem com a diversidade, isso não se concretiza plenamente na prática. Um exemplo clássico é a Lei 10.639, que trata das diretrizes curriculares para o ensino da cultura africana e afro-brasileira ${ }^{8,9}$. Foi criada a lei, foi criada a norma e, mesmo assim, não verificamos isso acontecendo no cotidiano de muitas escolas; pior ainda são as questões da população LGBT, para a qual sequer existe lei para se cobrar o cumprimento. Comemora-se na escola o dia do índio, as crianças pintam o índio; a questão da abolição da escravização também é vista. São datas emblemáticas trabalhadas de forma pontual e, na maioria das vezes, de forma estereotipada e perversa. Agora, no dia 17 
de maio ${ }^{v}$, a maioria das escolas nem sabem, nem lembram, nem citam a questão da luta pela LGBTIfobia. No geral, é selecionado o que e como se pode e o que não se pode ser trabalhado no espaço escolar. As pessoas LGBTI, com toda a abertura de hoje, ainda não conseguem que esse trabalho seja realizado. Ainda é difícil para quem está na gestão das escolas, na gestão dos sistemas educacionais federais, estaduais e municipais atuar decisivamente nessa questão e de forma qualificada de modo a prover uma educação para todos e inclusiva. Sabemos que existe autonomia dos sistemas, mas não percebemos a atuação da maioria deles na direção da aceitação pessoal e profissional das diferenças.

Que o respeito às diferenças possa ser central no currículo, que o assunto venha nos livros didáticos, que conste na formação inicial e contínua dos docentes, que venha também com projetos que incluam palestras; que venha a ser lembrado principalmente nos dias específicos de lutas, a fim de trazer para o público a importância de se discutir determinadas questões no espaço educacional, fazendo valer a sua máxima: a escola é um espaço para todos.

Reciis: Como você observa a relevância da sua pesquisa em relação às subjetividades, mas também como uma potência científica e política, atuando principalmente nos espaços educacionais?

Luma Andrade: A pesquisa segue uma linha de pensamento que não aquela das travestis nos campos da prostituição, mas com elas em outros espaços, no interior, nos pequenos lugarejos e dentro da escola. As travestis que estão no interior não têm acesso à indústria do silicone, mas têm uma outra forma de identificação e construção desse ser travesti, ou das travestilidades, com as formas possíveis que elas têm na construção do seu corpo, atravessado fortemente por uma questão de classe. É uma outra realidade, que não pode ser menosprezada por não estar associada às tecnologias mais avançadas. Contribuí com meu estudo, por meio da produção científica, com um outro olhar e uma outra percepção sobre as travestilidades. Dentro da minha vivência, eu tinha um entendimento sobre isso tudo, mas faltava trazer a discussão para a produção científica. O fato de ser a primeira travesti produzindo conhecimento sobre sua população revela outras subjetividades despercebidas por outros pesquisadores.

Isso é importante também para reflexão de algumas práticas sociais e políticas. O nome social nas escolas do estado do Ceará foi aprovado pelo Conselho Estadual de Educação, tendo como base o meu trabalho. Já estive na Câmara dos Deputados em Brasília, onde apresentei propostas que subsidiaram várias outras ações e algumas políticas, principalmente ligadas à questão do nome social. Estive ano passado no Conselho Nacional de Educação para realizar também a defesa do nome social, engendrando a aprovação da resolução assinada pelo ministro da Educação do período (2018). Então, é um trabalho que ainda hoje tem uma potência muito grande para fundamentação, para a elaboração de políticas públicas e para produzir uma mudança dentro desse contexto social.

A pesquisa contribuiu também para a criação, por exemplo, na Universidade da Integração Internacional da Lusofonia Afro-Brasileira (Unilab), onde atuo na docência, de disciplinas específicas e para o uso desse estudo como referência bibliográfica, não só na Unilab, como em outras universidades. Tive a oportunidade de participar da construção do Projeto Pedagógico do Curso (PPC) da Unilab. No processo de construção das disciplinas e das ementas, coloquei em discussão a necessidade de disciplinas para tratar de gênero e diversidade sexual. Conseguimos aprovar, por exemplo, a disciplina Educação, Gênero e Diversidade Sexual nos Países da Integração, pois a Unilab envolve diversos países de língua portuguesa. Recebemos

v Conhecido como o "Dia Internacional de Luta Contra a Homofobia, Bifobia e Transfobia". Esta data visa conscientizar a população sobre a luta contra a discriminação dos homossexuais, transexuais e transgêneros. 
várias pessoas do continente africano e de países que falam a língua portuguesa que vieram estudar aquivi ${ }^{\text {vi }}$ Colocamos as disciplinas não como optativas, como muitas vezes é praticado em algumas universidades. São disciplinas obrigatórias porque os profissionais que estamos formando têm de saber lidar com essas questões. Fiz questão de propor e me candidatar como a professora que iria lecionar algumas dessas disciplinas. Assim, sempre leciono disciplina específica para trabalhar com as questões de gênero e diversidade sexual. Os profissionais que estamos formando realizam reflexões, a partir de alguém que vivenciou tudo isso. A procura foi tão grande que conseguimos propor que essa discussão se estendesse para os demais cursos.

\section{Reciis: Ser doutora e travesti é uma transgressão ou resistência às normas?}

Luma Andrade: Nunca imaginei que eu seria a primeira. A primeira doutora travesti deste país. Nunca imaginei que seria a primeira docente travesti de uma universidade deste país. Nunca pensei nisso. Apenas fui seguindo. Fui seguindo os meus objetivos, meus ideais e foi uma surpresa quando, ainda no doutorado, o jornal 'Folha de S.Paulo' me procurou e fez um estudo que constatou que eu era a primeira doutora travesti do país ${ }^{10}$. Ora, se sou a primeira, logo o que acontece comigo não acontece com as outras então. Por que elas não estão chegando nesses lugares? O que está acontecendo? Percebe-se que isso não é motivo de alegria. Não é motivo de celebração. É motivo de reflexão. É preciso dizer que cheguei neste lugar de forma inédita, mas existem outras trajetórias para chegar até a existência de Luma, que são daquelas travestis que me antecederam. Só estou neste lugar por conta delas, porque elas resistiram principalmente na ditadura, resistiram em existir nos lugares públicos. Em palestras no Brasil inteiro e fora do país, as pessoas querem me identificar como trans: a professora trans. Na hora em que vou falar, tenho, na maioria das vezes, que corrigir: "Olha, eu sou uma travesti". Com todo respeito às pessoas que se identificam como transexuais, eu me identifico como travesti em respeito às que me antecederam. Não posso seguir na mesma forma tradicional de pensar que o termo travesti é algo negativo. Tenho o dever de mostrar que travesti é um ser humano que tem potencialidades como qualquer outro. Então, essa autoafirmação se refere a uma questão política e de reconhecimento histórico.

Vejo-me como uma outra possibilidade, principalmente quando vou a palestra, em lugares diversos, por ser uma, entre outras, fonte de inspiração para as travestis e transexuais que me revelam que conheceram minha história e, a partir dela, perceberam que poderiam buscar outras possibilidades de sobrevivência na sociedade. Recordo-me de uma colega professora ao relatar: "Luma, eu tenho uma aluna trans e falei com a mesma sobre a sua história e suas conquistas, sendo uma docente numa universidade federal. Ela olhou para mim e disse: E pode?” Percebe-se, então, a importância de disseminar esse conhecimento para chegar em todas. Para que elas não fiquem pensando que não podem. Elas têm o direito à educação. Não estou querendo dizer que elas não têm direito de buscarem a prostituição. Estou dizendo que elas têm outras possibilidades caso queiram.

Também é importante dizer que não se trata, às vezes, de uma questão de escolha, mas de oportunidades que vão aparecendo. Temos, em alguns momentos, a possibilidade de escolha, mas às vezes você não tem esta possibilidade. De certa forma, isso passa a ser uma história de transgressão. É você sair de uma forma

vi A Universidade da Integração Internacional da Lusofonia Afro-Brasileira é uma autarquia vinculada ao Ministério da Educação da República Federativa do Brasil, com sede na cidade de Redenção, estado do Ceará. Foi criada pela Lei no 12.289, de 20 de julho de 2010, e instalada em 25 de maio de 2011. De acordo com a legislação, a Unilab tem como objetivo ministrar ensino superior, desenvolver pesquisas nas diversas áreas de conhecimento e promover a extensão universitária, tendo como missão institucional específica formar recursos humanos para contribuir com a integração entre o Brasil e os demais países membros da Comunidade dos Países de Língua Portuguesa (CPLP), especialmente os países africanos, bem como promover o desenvolvimento regional e o intercâmbio cultural, científico e educacional. As atividades administrativas e acadêmicas da Unilab se concentram nos estados brasileiros do Ceará e da Bahia. No Ceará, a universidade conta com unidades nos municípios de Redenção e Acarape. Na Bahia, a Unilab está presente no município de São Francisco do Conde. 
de pensamento que restringe a sua existência para buscar um lugar onde você seja aceita, principalmente nos espaços das universidades, das escolas e no espaço de docente.

Ainda hoje estou num lugar de transgressão. As pessoas dizem: "Ah, a professora travesti não sofre mais nada”. No entanto, eu preciso me posicionar dentro do coletivo de professores e com alguns discentes. A resistência é o tempo todo, mas vou aproveitando para desconstruir determinados pensamentos e atitudes, afinal, a nossa presença não é capaz apenas de produzir estranhamentos e aversões, mas permite a convivência e a possibilidade de mudança de comportamento.

\section{Referências}

1. Andrade LN. A poluição do Rio Banabuiú pelas águas residuárias do município de Morada Nova-CE [dissertação]. Mossoró: Universidade do Estado do Rio Grande do Norte; 2006.

2. Bento B. A reinvenção do corpo: sexualidade e gênero na experiência transexual. Rio de Janeiro: Garamond; 2006.

3. Pelúcio L. Três casamentos e algumas reflexões: notas sobre conjugalidade envolvendo travestis que se prostituem. Rev. Estud. Fem. 2006:14(2):522-34. doi: http://dx.doi.org/10.1590/S0104$\underline{026 \times 2006000200012}$

4. Foucault M. Microfísica do poder. Rio de Janeiro. 26. ed. Rio de Janeiro: Graal; 1979.

5. Foucault M. Vigiar e punir: nascimento da prisão. Petrópolis: Vozes; 1987.

6. Andrade LN. Travestis na escola: assujeitamento e resistência à ordem normativa [tese na internet]. Fortaleza: Universidade Federal do Ceará; 2012 [citado em 2019 jun. 20]. Disponível em: http://www. repositorio.ufc.br/handle/riufc/7600.

7. Presidência da República (BR). Casa Civil. Lei No 9.394 de 20 de dezembro de 1996. Estabelece as diretrizes e bases da educação nacional. DOU [Internet]. 1996 [citado em 2019 jun. 18]. Disponível em: http://www.planalto.gov.br/ccivil 03/leis/19394.htm

8. Presidência da República (BR). Casa Civil. Lei 10.639/2003 de de 9 de janeiro de 2003. Altera a Lei no 9.394, de 20 de dezembro de 1996, que estabelece as diretrizes e bases da educação nacional, para incluir no currículo oficial da Rede de Ensino a obrigatoriedade da temática "História e Cultura AfroBrasileira", e dá outras providências. DOU [Internet]. 2003 [citado em 2019 jun. 18]. Disponível em: http://www.planalto.gov.br/ccivil 03/leis/2003/L10.639.htm

9. Presidência da República (BR), Ministério da Educação. Plano Nacional de Implementação das Diretrizes Curriculares Nacionais da Educação das Relações Étnico-raciais e para o Ensino de História e Cultura Afro-Brasileira e Africana [Internet]. 2013 [citado em 2019 jun. 18]. Disponível em: http://www.crianca. mppr.mp.br/arquivos/File/publi/mec/diretrizes curriculares etnicorraciais mec 2013.pdf

10. Fernandes K. Travesti vence o preconceito e faz doutorado. Folha de S.Paulo [Internet]. 2009 [citado 12 fev. 2009]. Disponível em: http://www1.folha.uol.com.br/folha/educacao/ult305u485921.shtml 